\title{
Effect of Blood Contamination and Decontamination Procedures on the Microtensile Bond Strength of a New Self-etch Adhesive: An in vitro Study
}

\author{
${ }^{1}$ Asiya Shaikh, ${ }^{2}$ Vivek Hegde, ${ }^{3}$ Srilatha Shanmugasundaram
}

\begin{abstract}
Aim: The aim of the study was to evaluate the effect of blood contamination and decontamination procedures on the microtensile bond strength of a new self-etch adhesive before and after curing.
\end{abstract}

Materials and methods: A total of 90 human extracted mandibular molars were stored in $0.5 \%$ thymol solution and distilled water. Midcoronal sections were obtained using a diamond disk and the dentin surface was ground with 320 grit SIC abrasive paper. Universal self-etch adhesive (3M ESPC) and Filtex Z-250 resin composite were used .The dentin specimens were randomly divided into nine groups: Control group, group l-blood contamination before curing, group II-blood contamination before curing followed by air drying, group III-blood contamination before curing followed by rinsing with water and air drying, group IV_-blood contamination before curing followed by rinsing with water, air dry, and reapplication of bonding agent, group V-blood contamination after curing, group VI-blood contamination after curing followed by air dry, group VII-blood contamination after curing followed by rinsing with water and air drying, group VIII_-blood contamination after curing followed by rinsing with water, air dry, and reapplication of bonding agent. The microtensile bond strength was measured by universal testing machine and the data were analyzed by one-way analysis of variance (ANOVA) followed by Tukey's post hoc test.

Results: The contamination groups (I, V) showed the least bond strength followed by the decontamination groups (II, III, VI, VII). The reapplication groups (IV, VIII) restored the bond strength equal to control group.

Clinical significance: A contamination-free area is required for adequate adhesion. It is important to rule out measures to prevent and manage contamination, so as to achieve durable seal between composite resin and tooth surface.

Keywords: Blood contamination, Filtex Z-250, Microtensile bond strength, Single-bond universal adhesive.

\footnotetext{
${ }^{1}$ Postgraduate Student, ${ }^{2}$ Professor and Head, ${ }^{3}$ Associate Professor

${ }^{1-3}$ Department of Conservative Dentistry and Endodontics, M. A. Rangoonwala College of Dental Sciences \& Research Centre Pune, Maharashtra, India

Corresponding Author: Asiya Shaikh, Postgraduate Student Department of Conservative Dentistry and Endodontics, M. A. Rangoonwala College of Dental Sciences \& Research Centre Pune, Maharashtra, India, Phone: +919552978658, e-mail: drasiyashaikh786@gmail.com
}

How to cite this article: Shaikh A, Hegde V, Shanmugasundaram S. Effect of Blood Contamination and Decontamination Procedures on the Microtensile Bond Strength of a New Selfetch Adhesive: An in vitro Study. Int J Experiment Dent Sci 2017;6(2):80-83.

\section{Source of support: Nil}

Conflict of interest: None.

\section{INTRODUCTION}

The increasing demand for esthetic restoration has led to a drastic increase in clinical applications of and intensive research on adhesives. The fundamental requirement of resin composite is durable adhesion of the composite to tooth structure. In order to generate a durable seal between the restoration and tooth surface, successful adhesion without contamination is necessary. ${ }^{1-4}$ Contamination with saliva and blood commonly occurs during the procedure; rubber dam isolation is the ideal way to achieve a dry field; however, in clinical routine, it is not always feasible.

There are several studies that indicate that blood contamination significantly reduces the bond strength. According to Kaneshima et $\mathrm{al}^{5}{ }^{5}$ the effect greatly varies on the surface condition of adherent.

Self-etch adhesives have gained popularity among the clinicians since they are less technique-sensitive, provide ease of application, and reduce clinical steps. Although the short application reduces the risk of contamination, however, it may be sometimes impossible to maintain a contamination-free area, especially when restoring class II and class V. There are limited studies investigating the effect of blood contamination on the microtensile bond strength of self-etch adhesives.

The purpose of the study was to evaluate the effect of blood contamination and various decontamination procedures on the microtensile bond strength of self-etch adhesives at different stages before and after curing.

\section{MATERIALS AND METHODS}

Ninety extracted noncarious mandibular molars stored in $0.5 \%$ thymol solution and distilled water were used. The teeth were horizontally sectioned to obtained flat 

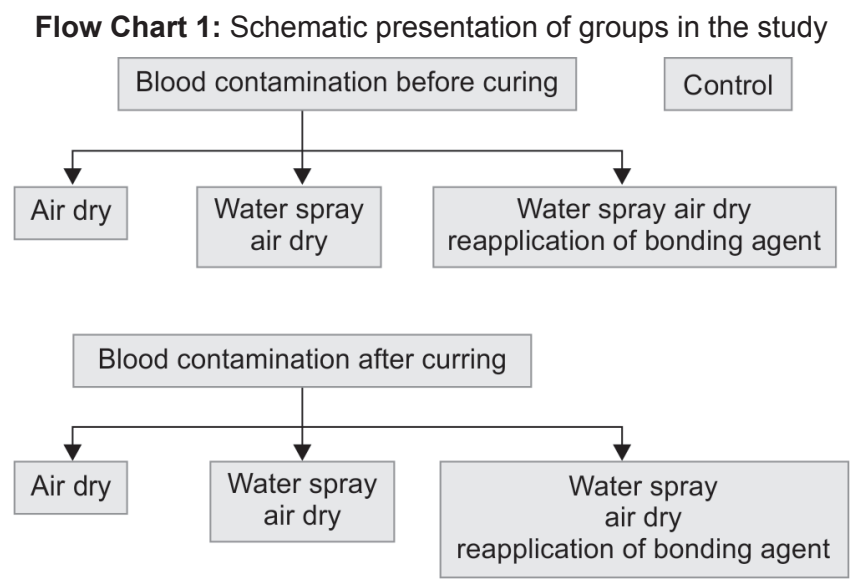

dentin disk of approximately $1.5 \times 2 \mathrm{~cm}$ using a diamond saw. To obtain clinically relevant smear layer, the dentin surface was ground using 320 grit SIC abrasive paper (Emery Co.In).

The blood sample was obtained from one of the authors. Fresh venous blood was collected from the vena mediana using a disposable syringe. The withdrawn blood was used immediately. The samples were randomly divided into 9 groups based upon following factors: The step in the bonding sequence when contamination occurred (before or after curing) and the decontamination procedures (air dry, water spray, and reapplication) as shown in Flow Chart 1.

\section{Control Group}

Self-etch adhesive (single-bond universal 3M) was applied on the dentin surface according to manufacturer's instruction using a microbrush and light cured for 10 seconds.

Group I: Self-etch adhesive was applied on the dentin surface, which was followed by contamination using a drop of blood applied directly on the surface, left undisturbed for 15 seconds, and light cured for 10 seconds.

Group II: The same procedure was followed as mentioned above. Additionally after contamination, the decontamination procedure, i.e., air dry was performed $10 \mathrm{~cm}$ away from the target tissue for 10 seconds followed by light curing for 10 seconds.

Group III: After contamination of the samples, the decontamination procedure was carried out using water spray $10 \mathrm{~cm}$ away from target tissue followed by air dry for 10 seconds and light cured for 10 seconds.

Group IV: After contamination, the decontamination procedure using water spray followed by air dry was carried out, and the adhesive was reapplied and light cured for 10 seconds.

Groups V, VI, VII, and VIII: The same procedure performed in group I, II, III, and IV were repeated in group V, VI, VII, and VIII respectively, except for the stage of contamination, which was considered after curing in these groups.

A nanohybrid composite resin (Filtex Z-250, color A3-3M ESPE, USA) was placed in increments into Teflon cylinders $(3 \times 8 \mathrm{~mm})$. Each increment was light cured for 40 seconds. All the specimens were stored in distilled water for 24 hours followed by thermocycling $\left(5-55^{\circ} \mathrm{C} 15\right.$ seconds dwell time). After storage, the specimens were debonded under tension using a universal testing machine (Model No. STS 435) at a cross-head speed of $3 \mathrm{~mm} / \mathrm{minute}$. The bond strengths were expressed in $\mathrm{MPa}$.

\section{RESULTS}

The microtensile bond strengths for the different groups are summarized in Table 1. The data were analyzed by one-way ANOVA followed by Tukey's post hoc test. All the contamination groups showed lower bond strength. Groups I (1.02) and V (1.08) showed the least bond strength of $p>0.05$ when analyzed statistically. Groups IV (20.0) and VIII (21.09), which were the reapplication groups, restored the bond strength equal to control group (23.2) of $p>0.05$. Decontamination groups II (9.08) and VI (10.0) showed significantly lower bond strength with no statistical difference ( $p>0.05$ ), group III (0) showed no bond strength, whereas group VII showed bond strength (12.8) with statistically significant difference (Table 2 and Graph 1).

\section{DISCUSSION}

Contamination of the operating field is a problem, which occurs while restoring deep proximal and cervical

Table 1: Adhesive used in the study

\begin{tabular}{lll}
\hline Adhesive & Manufacturer & Composition \\
\hline Single-bond & 3M ESPE & 10-Methacryloyloxydecyl \\
universal & St. Paul, MN, & $\begin{array}{l}\text { dihydrogen phosphate } \\
\text { monomer, dimethacrylate resin, } \\
\text { 2-hydroxyethyl methacrylate, } \\
\text { vitrebond copolymer, filler, } \\
\text { ethanol, water, initiators, silane }\end{array}$ \\
& &
\end{tabular}

Table 2: One-way ANOVA followed by Tukey's post hoc test

\begin{tabular}{lllll}
\hline Groups & $\begin{array}{l}\text { Number of } \\
\text { samples }\end{array}$ & Mean & $\begin{array}{l}\text { Standard } \\
\text { deviation }\end{array}$ & p-value \\
\hline Control & 10 & $23.2^{\mathrm{a}}$ & 6.2 & \\
Group I & 10 & $1.02^{\mathrm{b}}$ & 2.8 & \\
Group II & 10 & $9.08^{\mathrm{c}}$ & 6.8 & \\
Group III & 10 & 0 & 0 & $<0.001^{\text {** }}$ \\
Group IV & 10 & $20.0^{\mathrm{a}}$ & 5.6 & \\
Group V & 10 & $1.08^{\mathrm{b}}$ & 2.4 & \\
Group VI & 10 & $10.0^{\mathrm{c}}$ & 2.3 & \\
Group VII & 10 & $12.8^{\mathrm{c}}$ & 8.4 & \\
Group VIII & 10 & $21.9^{\mathrm{a}}$ & 4.1 & \\
\hline Pro.0D1,
\end{tabular}

$p<0.001$, highly significant; same letters indicate no significant differences between groups $(p>0.05)$; ${ }^{* *}$ Indicate highly significant statistically 


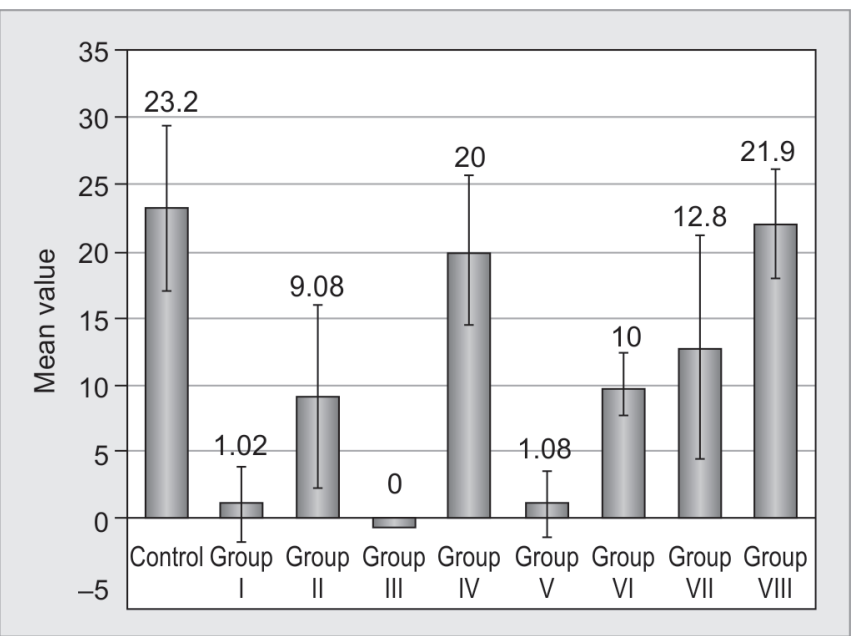

Graph 1: Mean microtensile bond strength of different groups in this study (control 23.2, group I 1.02, group II 9.08, group III 0, group IV 20, group V 1.08, group VI 10, group VII 12.8, group VIII 21.9)

lesions. Rubber dam isolation is mandatory to achieve a dry field; however, in many clinical situations, the placement is difficult and contamination may occur. In this study, the effect of blood contamination on microtensile bond of self-etch adhesive was evaluated. Contamination of blood was carried out before and after curing along with different decontamination procedures that are commonly used clinically.

The adhesive strategy of self-etch adhesive relies on smear layer dissolution. Hence, for laboratory testing of self-etch adhesives, it is recommended to form a smear layer that closely resembles that of which is formed clinically. Oliveira et $\mathrm{al}^{6}$ demonstrated that 320 grit silicon carbide paper creates a clinically relevant smear layer. The carbide and diamond burs and disk, which are most frequently used to obtain a dentin specimen, create a smear layer, i.e., not clinically relevant. ${ }^{7,8}$ Hence, in this study, the enamel was removed with a diamond disc followed by wet sanding on the dentin surface with 320 grit silicon carbide paper in order to obtain a standardized smear layer.

There are various studies showing that blood contamination affects the bond strength. However, the literature contains many discrepancies, particularly, in the terms of type of blood used and the storage period. There are two opinions with regards to type of blood to be used; one recommends fresh blood, ${ }^{9}$ while the others recommend blood with anticoagulant. ${ }^{5,10}$ The influence of blood contamination on bond strength is attributed to its high protein content that, along with macromolecules, such as fibrinogen and platelets that form a film on the dentin surface, obstructs the penetration of the adhesive system into dentinal tubules. ${ }^{5}$ Adding an anticoagulant to blood will not allow the formation of a blood film, ultimately giving confounding results. Hence, fresh blood that was immediately drawn was used in this study in order to simulate the clinical condition.

Self-etch adhesives have gained popularity due to reduced clinical steps that probably will reduce the risk of contamination. In this study, single-bond universal adhesive (3M) was used, which is a seventhgeneration bonding agent, which is both hydrophilic and hydrophobic in nature thus, providing good strength at both wet- and dry-etched dentin. It provides a distinct hybrid layer and resin tags, which improve bond strength. Hence, single-bond universal adhesive was selected in this study to evaluate whether contamination with blood affects the bond strength.

The bond strength achieved in the control group was 23.2 MPa. Groups I and V, which were the contamination groups, showed significantly lower bond strength, which cannot be clinically acceptable. The various decontamination procedures that are commonly used by clinicians, i.e., air dry, water spray, and reapplication of adhesive are considered in this study. The decontamination group II showed lower bond strength than group VI, but was not statistically significant ( $p>0.05$ ). It is because decontamination using air dry is not sufficient enough to remove the contaminant from the dentin surface. The decontamination group III showed immediate debonding, and, hence, the bond strength recorded was 0 . Group VII showed bond strength of $12.8 \pm 8.4$, which is relatively less as compared with the control group. Hence, it is clear that the decontamination procedure, i.e., air dry followed by water spray is not sufficient to achieve adequate bond strength. The reason behind the poor bond strengths with groups II, III, V, and VI might be the fact that the remnants of blood protein or excess water, which was not removed, could have impaired the adhesion. The decontamination groups IV and VIII showed bond strength equal to control, and, hence, it is advisable that whenever the tooth is contaminated, it is necessary to clean the tooth of the contaminant and reapply the adhesive. The findings in this study demonstrate that single-bond universal adhesive, when tested, allowed for a satisfactory adhesion when not contaminated or when the adhesive is reapplied.

\section{CONCLUSION}

Blood contamination affects the microtensile bond strength of self-etch adhesive to dentin. In addition, none of the decontamination procedures used in this study restored the bond strength. Hence, in a clinical scenario, if blood contamination occurs, thorough cleaning and rinsing followed by repeating the bonding procedure are recommended. In addition to this, alternative materials should be considered for restoration, if blood contamination cannot be avoided. 
Within the limitations of this in vitro study, it can be concluded that blood contamination should be avoided when using self-etch adhesives.

\section{REFERENCES}

1. Yoo HM, Pereira PN. Effect of blood contamination with 1 step self etch adhesives on microtensile bond strength to dentin. J Oper Dent 2006 Nov-Dec;31(6):660-665.

2. Abdalia AL, Davidson CL. Bonding efficiency and interfacial morphology of one bottle adhesive to contaminated dentin surfaces. Am J Dent 1998 Dec;11(6):281-285.

3. Dietrich T, Kramer M, Losche GM, Wernerke KD, Roulet JF. Influence of sandwich class II restoration. J Oper Dent 2000 Sep-Oct;25(5):401-410.

4. Tachibana A, Castanho GM, Vieira SN, Matos AB. Influence of bond strength of self etching adhesive to dental tissues. J Adhes Dent 2011 Aug;13(4):349-358.

5. Kaneshima T, Yatani H, Kasai T, Watanabe EK, Yamashik A. Influence of blood contamination on bond strength between dentin and adhesive resin cement. Oper Dent 2000 MayJun;25(3):195-201.

6. Oliveira SS, Pugach MK, Hilton JF, Watanabe LG, Marshall SJ, Marshall GW Jr. The influence of the dentin smear layer on adhesion: a self-etching primer vs. a total-etch system. Dent Mater 2003 Dec;19(8):758-767.

7. Koibuchi H, Yasuda N, Nakabayashi N. Bonding to dentin with a self-etching primer: the effect of smear layers. Dent Mater 2001 Mar;17(2):122-126.

8. Ogata M, Harada N, Yamaguchi S, Nakajima M, Pereira PN, Tagami J. Effects of different burs on dentin bond strengths of self-etching primer bonding systems. Oper Dent 2001 JulAug;26(4):375-382.

9. Dietrich T, Kramer M, Roulet JF. Blood contamination and dentin bonding -effect of anticoagulant in laboratory studies. Dent Mater 2002 Mar;18(2):159-167.

10. Itch T, Fukushima T, Inoue Y, Miyazaki K. Effect of water, saliva and blood contamination on bonding of metal brackets with a GMETA/MMA/TBB resin to etched enamel. Am J Dent 1999 Dec;12(6):299-304. 